\title{
Learning from the Environment: Evaluation Research and Experience Based Architectural Pedagogy
}

\author{
Dr Ashraf M. Salama, Associate Professor of Architecture \\ College of Environmental Design, King Fahd University of Petroleum and Minerals \\ Email: asalama@kfupm.edu.sa
}

\begin{abstract}
Debates on higher education assert that a university mission should foster a campus environment that nurtures exploration and critical thinking. Today, inquiry and investigation are viewed as activities central to undergraduate programs. This paper advocates the integration of research into undergraduate architectural education by arguing for the exposure of students to primary source materials that enable them to get as close as possible to the realities being studied. The paper generates a critical discussion on idiosyncrasies and misconceptions about knowledge acquisition and production. It explores the status of research methods courses in selected undergraduate architecture programs from the Middle East. An attempt at integrating evaluation research and experiential learning into architectural pedagogy is presented as a case from King Fahd University of Petroleum and Minerals (KFUPM). A framework toward a transformative architectural pedagogy is introduced to complement traditional teaching techniques. It outlines a number of related concepts together with the supporting learning mechanisms, activities, and settings. It is suggested that this framework would invigorate the capabilities of future architects to be more culturally and environmentally responsive, critical thinkers, and engage in the production of knowledge.
\end{abstract}

Keywords: Evaluation Research, Experiential Learning, Research Methods, Design Studio, Lecture Courses 
A.M. Salama: Learning from the Environment: Evaluation Research and Experience Based Architectural Pedagogy

\section{Introduction}

Emerging concerns about undergraduate education in universities present new opportunities for us as academics to strengthen our programs, to enhance our role in shaping undergraduate education, and to improve the quality of that education. These concerns are not new; they have emerged in one form or another, from early reform efforts by John Dewey and Alfred Whitehead to the experimental colleges of the 1960s. However, in the last few years, the level of concern has intensified and the flood of reports and position papers has crested at an alarmingly high level. Reports with catchy and compelling titles continue to roll off the presses with increasing regularity. Examples of these titles are: "Shaping the Future: New Expectations for Undergraduate Education in Science, Mathematics, Engineering and Technology," and "UNESCO Declaration on Higher Education." The reports, in turn, have generated intensive discussions in the literature of just about every discipline. Most important is not the quantity, but the focus of this new round of debate; an emphasis on issues central to our own mission that simply involves the development of research skills and critical thinking abilities through active learning.

A visionary report was published in 1998 by the Boyer Commission: Reinventing Undergraduate Education: A Blueprint for America's Research Universities, establishing links between many of the concerns in a well-developed critique of undergraduate education. The report's conclusions, while aimed at research universities, apply to most institutions of higher education worldwide, whether classed as research institutions or not (BCEURU, 1998). According to Schaffner et al. (1999) since the release of the report, it has been a catalyst for discussion, defensive action, and reform at many institutions. For the discipline of architecture, similar reports have been introduced to the international community including "UIAUNESCO Charter of Architectural Education-1996", the Carnegie Foundation's report on "A New Future for Architectural Education and Practice-1996" and the AIAS report on "the Re-design of Studio Culture-2002". These reports indicate that undergraduate education does not take full advantage of the unique opportunities available in higher education institutions. Links between undergraduate education, professional practice, and faculty research are often oversimplified; opportunities to enrich and strengthen undergraduate education through exposure to the research process are missed.

This paper advocates the involvement of undergraduate architecture students in research by introducing a framework within which experiential learning and evaluation research can be incorporated into architectural pedagogy. It argues for exposing students to primary source materials, and for educating them about the production of knowledge. This is proposed in order to complement traditional teaching practices that emphasise secondary source information and the 
consumption of knowledge by offering students ready-made interpretations in theory and lecture courses. Primary sources enable students to get as close as possible to what actually happened (is happening) during a historical event or time period.

The methodology adopted in this paper is based on reviewing the recent literature on undergraduate architectural education by conducting a preliminary inductive analysis. The aim is to establish a critical discussion of idiosyncrasies and misconceptions about knowledge acquisition and production in architectural education, while investigating the status of research methods courses in selected undergraduate architecture programs from the Middle East. The analysis corroborates the need for integrating evaluation research and experiential learning in architectural pedagogy. An attempt at integration is presented as a case from King Fahd University of Petroleum and Minerals (KFUPM) that sheds light on mechanisms that foster desired integration. A more consolidated framework toward a transformative architectural pedagogy is introduced while illustrating related concepts, and supporting learning mechanisms, activities, and settings.

\section{The Crux of the Problem: On Traditional Teaching Practices}

“.... Architects who have aimed at acquiring manual skills without scholarship have never been able to reach a position to correspond with their pains..." Marcos Vitruvius Pollio, Ten Books on Architecture, 100 B.C.

There has been-and still is - a continuous debate among architects and architectural educators about the role of knowledge and research in architecture as a discipline and profession (Salama, 1996; Sutton, 1984). Whether in developed or developing countries, many in architecture still think of researchers as people in white smocks and thick glasses searching for the mystery and the unknown. In response, scholars and educators have emphasised that research should be viewed as part of everyday actions and experiences. They argue, and rightly so, that traditional teaching practices have long encouraged students to develop form manipulation skills by emphasising intuition, reflective observation, and concept formation (Juhasz, 1981; Salama, 1995; Sanoff, 2003; Seidel, 1994). However, these practices are hypothetical; largely unconcerned with real life situations, neglecting equally important skills that can be enhanced through experiential learning, research, or real interaction with the realities being studied (Gerlenter, 1988; Mazumdar, 1993).

In traditional teaching practices, architecture students are typically encouraged to conduct site visits and walkthrough the built environment in order to observe different phenomena. Unfortunately however, research indicates that these visits and exercises are simply casual and are not structured in any form of investigation or inquiry. As a result, students do not realize what to see and what to look for in the 
built environment. The case would be worse when educators attempt to offer students ready made interpretations about the physical world in lectures and seminar classes, leading to students' inability to think critically or develop their intellectual skills. This handicaps their abilities to gather, analyse, synthesise, and process different types of information. Traditional teaching practices have contributed to the view of architecture as an art-based profession oversimplifying other critical views of it as a knowledge-based or research based educational discipline and profession (Salama, 2005). In response, current discourses have heavily emphasised the value of knowledge acquisition and of the introduction of research based pedagogy (Fisher, 2004; Groat, 2000).

\section{Idiosyncrasies and Misconceptions in Undergraduate Architectural Education: On the "What" and "How" of Knowledge}

While architectural educators strive to impart the requisite knowledge necessary for successful practice, the way knowledge is transmitted has significant professional and social implications. Concomitantly, there is an urgent need to confront issues that pertain to the nature of reality (what) and the way in which knowledge about that reality is conveyed to our budding professionals (how). Traditional teaching practices suggest that gaps exist between "what" and "how". Along this line of thinking, Amos Rapoport (1994) argues for the need for the discipline of architecture to develop a quantifiable body of knowledge by calling for a dramatic departure from the art paradigm that the profession and its education are based upon to one based on science and research. Rapoport introduced a number of questions underlying the heading of "knowledge about better environments"; these are: what is better, better for whom and why it is better? (Rapoport, 1994). A set of idiosyncrasies and misconceptions can be envisaged in this context based on reviewing the recent literature on architectural education and on investigating the results of a number of surveys of architectural educators (Anthony, 1991; Cuff, 1991; Koch, et al., 2002; Mazumdar, 1993; Nicol and Pilling, 2000; Salama, 1995, 2002; Sanoff, 2003; Schon, 1981, 1983, 1985, 1988; Stamp, 1994; Teymur, 1996). One should note that this literature indicates that such misconceptions represent syndromes that characterize teaching practices in many schools of architecture worldwide.

\section{Artistic versus Socio-Cultural Paradigms}

The current system of architectural education tends to socialize its members teachers and students - into a predominantly artistic paradigm that emphasizes personal feelings, subjective judgments, intuition, and imagination at the expense of social and professional responsibilities. In order for future architects to function within cultural contexts and to address societal realities, the socio-cultural paradigm should be introduced. In essence, this requires the development of students' skills that go beyond the capacity of the artistic paradigm. The intention here is to add and develop, not to replace or omit. 
A.M. Salama: Learning from the Environment: Evaluation Research and Experience Based Architectural Pedagogy

\section{The Real versus the Hypothetical}

Educators tend to offer students hypothetical experiments in the form of hypothetical design projects where many contextual variables are neglected. In this respect, experiential learning should be introduced. Real life experiences can provide students with opportunities to understand the practical realities and different variables that affect real-life situations. Typically, educators focus on offering students readymade interpretations about the built environment rather than developing their abilities to explore issues that are associated with the relationship between culture and the built environment. If they do, they place emphasis on one single culture, which is their own.

\section{Science as a Body of Knowledge versus Science as a Method of Exploration}

When teaching any body of knowledge, educators tend to present it as a body of facts and theories and as a process of scientific criticism. The processes that led up to this product are always hidden and internalized. There should be a distinction between the types of knowledge resulting from research in architecture and students should be made aware of them and experience them as well. First, knowledge that results from research that seeks to understand the future through a better understanding of the past; research that tests accepted ideas. Second, knowledge that results from research that develops new hypotheses and visions; research that probes new ideas and principles which will shape the future.

\section{Learning Theories about the Phenomena versus Getting the Feel of the Behaviour of the Phenomena}

Knowledge is usually presented to students in a retrospective way where abstract and symbolic generalizations used to describe research results do not convey the feel of the behaviour of the phenomena they describe; the late Donald Schon emphasized this view in 1988. The term retrospective here means extensive exhibition of the performance of the work of an architect over time. In essence, the analysis of precedents as part of the curriculum should be introduced. How projects were created and in what context, what was the client nature and intentions, how the project was delivered, and how construction was undertaken are integral parts of learning. The story telling teaching mode carried out by educators in lecture and theory courses tends to ignore these issues.

\section{Knowledge versus Design}

The architectural design studio - the backbone of architectural education - rarely includes any research activity, based on the view that the content of design should be directed toward practical ends. It can be argued here that knowledge is not a substitute for architectural imagination but inadequate knowledge would handicap the general level of design. Being satisfied to manipulate formal configurations does not 
provide insights into the human experience. If the different types of knowledge which architecture requires are ignored, the profession would lose its credibility in the eyes of society. Simply, different types of knowledge should be integrated into design assignments.

In the context of discussing the preceding idiosyncrasies, it should be noted that recent years have witnessed intensive discussions on the value of introducing real life issues in architectural education teaching practices (Morrow, 2000; Morrow et al., 2004; Romice and Uzzell, 2005; Salama, 1996; Sanoff, 2003, and Sara, 2000). However, while published experiences have debated innovative practices exemplified by exposing students to primary source materials in studio processes, little emphasis has been placed upon how real life issues could be introduced in theory and lecture courses.

\section{The Status of Research in Undergraduate Architectural Education: Cases from the Middle East}

Typically, lecture based courses offered in undergraduate programs of architecture involve a research component in the form of library research activities or site visits. However, it is important to investigate the status of research methods as a course offered to architecture students. An investigation of fifteen undergraduate programs in eight Middle Eastern countries was conducted based on a preliminary content analysis of their published online and printed prospectuses (Table 1).

Table 1: Research methods related courses in 15 undergraduate architectural programs from the Middle East.

\begin{tabular}{|c|c|c|}
\hline Country & University & $\begin{array}{l}\text { Research Methods Related } \\
\text { Courses }\end{array}$ \\
\hline Bahrain & University of Bahrain & $\begin{array}{l}\text { - Research Methods in Architecture } \\
\text { (elective) }\end{array}$ \\
\hline \multirow[t]{3}{*}{ Egypt } & Al Azhar University & - Research and Report Writing \\
\hline & Cairo University & $\begin{array}{l}\text { - Scientific Methods and Decision } \\
\text { Making }\end{array}$ \\
\hline & Misr International University- MIU & $\begin{array}{l}\text { - Research Methods in Architecture } \\
\text { \& Urban Design }\end{array}$ \\
\hline \multirow[t]{4}{*}{$\begin{array}{l}\text { Kingdom of Saudi } \\
\text { Arabia }\end{array}$} & $\begin{array}{l}\text { King Fahd University of Petroleum \& } \\
\text { Minerals- KFUPM }\end{array}$ & $\begin{array}{l}\text { - Senior Project Programming \& } \\
\text { Preparation }\end{array}$ \\
\hline & King Faisal University- KFU & $\begin{array}{l}\text { - Research Methods } \\
\text { - Research and Programming }\end{array}$ \\
\hline & King Saud University- KSU & $\begin{array}{l}\text { - Programming of Architectural } \\
\text { Projects }\end{array}$ \\
\hline & King Abdul Aziz University & - Graduation Project Research \\
\hline Kuwait & Kuwait University & • - - - \\
\hline \multirow[t]{2}{*}{ Lebanon } & American University of Beirut- AUB & • - - \\
\hline & Beirut Arab University & • - - - \\
\hline Oman & Sultan Qaboos University & • - \\
\hline \multirow[t]{2}{*}{ Syria } & Aleppo University & • - - \\
\hline & Damascus University & • - - \\
\hline $\begin{array}{l}\text { United Arab } \\
\text { Emirates }\end{array}$ & $\begin{array}{l}\text { United Arab Emirates University- } \\
\text { UAEU }\end{array}$ & - Design and Research Methods \\
\hline
\end{tabular}


A.M. Salama: Learning from the Environment: Evaluation Research and Experience Based Architectural Pedagogy

The investigation reveals several observations that can be exemplified as follows:

- $\quad$ Ten research methods related courses are offered in the fifteen programs under different titles; of these, there are nine offerings within the core curriculum while one course is offered as elective.

- In six programs out of the fifteen, research does not appear to be of concern where no courses are offered.

- $\quad$ Philosophy statements and objectives of the programs do not refer to research, knowledge acquisition or application, experiential learning, evaluation studies, or interaction with real life issues. However, research methods appears to be of concern in some programs either as an independent course as in the cases of King Faisal , Al Azhar, and Cairo Universities, or as a subject linked to design as in the case of United Arab Emirates University, or directly related to senior and graduation projects as in the case of King Fahd University. In these three cases, contents are similar where research methods, techniques and applications are introduced with emphasis placed on offering students a spectrum of techniques including literature review, data gathering, analysis and presentation, building users needs analyses, and evaluation of existing buildings; methods of architectural programming; and criticism of designed environments.

- $\quad$ Course contents do not show if these techniques are based on the evaluation of existing environments or other forms of experiential learning. As well, they do not indicate if the techniques are implemented in a systematic manner.

Within the limits of this investigation, it can be stated that there is a growing awareness of the value of introducing research methods in undergraduate architectural education in the programs examined. While some scholars may argue that studying curricula is not sufficient to evaluate the quality of education, it should be noted that philosophy statements and course contents always reflect the profile and the major areas of interest that characterize an undergraduate program. However, whether research that is offered in research methods courses or in other theory and lecture courses have impacted the quality of learning or enhanced students' skills in acquiring and applying knowledge remains a critical question that represents a challenge. 


\section{Evaluation Research and Experiential Learning in Architectural Education: Establishing the Link}

Evaluation is an area of research and a mental activity devoted to collecting, analyzing, and interpreting information. Evaluation studies in architecture are intended to provide reliable, useful, and valid information. Evaluation literature conveys three major objectives of evaluation research that can be exemplified by developing a data base about the quality of the built environment, identifying existing problems or needs and their characteristics, and providing a basis for predicting the quality of future environments (Sanoff, 1992; Zube, 1981).

Several education theorists including Benjamin Bloom; David Kolb; Jean Piaget; John Dewey; and Paulo Freire voiced the opinion that experience should be an integral component of any teaching/learning process. Their work can be traced back to the famous dictum of Confucius around $450 \mathrm{BC}$ "Tell me and I will forget. Show me and I may remember. Involve me and I will understand." Experiential learning refers to learning in which the learner is directly in touch with the realities being studied (Keeton and Tate, 1978). It is contrasted with learning in which the learner only reads about, hears about, talks about, writes about these realities but never comes in contact with as part of the learning process. Mistakenly, some educators equate experiential learning only with "off campus" or "non-classroom" learning. However, in architectural pedagogy a class in history or theory of architecture might incorporate periods of student practice on theory exercises and critical thinking problems rather than consisting entirely of lectures about theories of architecture and the work of famous architects (O'Reilly, 1999; Salama et al., 2002). Similarly, a class in human-environment interactions might involve critical analysis exercises on how people perceive and comprehend the built environment. Both classes might involve field visits to buildings and spaces where students are in close contact with the environment, exploring culture, diversity, people behaviour, and be part of that environment. All of these mechanisms involve an experiential learning component.

Learning through experience involves not merely observing the phenomenon being studied but also doing something with it, such as testing its dynamics to learn more about it, or applying a theory learned about it to achieve some desired results. Evaluation as a valuable research vehicle needs to be introduced both in lecture courses and design studios, establishing a knowledge base about the built environment that has the capability of endowing students with more control over their learning, knowledge acquisition, and design actions and decisions (Salama, 1999). This argument corresponds with a recent argument introduced by John Habraken when he argues that:

We need to teach knowledge about everyday environment. How it is structured, what we can learn from historic and contemporary evidence, how 
different examples compare, how it behaves over time and responds to change of inhabitation or other circumstances... Teaching architecture without teaching how everyday environment works is like teaching medical students the art of healing without telling them how the human body functions. You would not trust a medical doctor who does not know the human body. Knowledge of everyday environment must legitimize our profession... (Habraken, 2003, p 40).

Linking evaluation research and experiential learning, one can argue that architecture students need to be involved in evaluation processes that should be conducted objectively and systematically - not through casual interviews or observations that may only reveal what is already known. In this context, they learn about problems and potentials of existing environments and how they meet people's needs, enhance and celebrate their activities, and foster desired behaviours and attitudes.

The results of the literature reviews convey that while there have been several attempts to incorporate evaluation research into architectural pedagogy; it would appear that they did not go beyond individual attempts of committed scholars and educators. Thus, one could argue that traditional teaching practices do not utilize experiential learning as a tool that addresses the dialectic relationship between people and their environments and that helps students understand and comprehend the multifaceted nature of the built environment.

\section{A Case from KFUPM: An Attempt at Integration}

In "Socio-Cultural Factors in Design" elective course offered by the department of architecture at KFUPM and taught recently by the author, an attempt was made to integrate evaluation research through experiential learning in order to get students involved in the production of knowledge while exposing them to primary sources of information. This was performed by assigning two major exercises; the first was "Contemplating Settings," and the second was "Procedural Evaluation". The two exercises adopt the concepts of the built environment as an open text book and as a teaching tool.

\section{Contemplating Settings}

In the first five weeks, students were introduced to a number of socio cultural and behavioural phenomena that include privacy, personal space, territoriality, crowding and density (Figure 1). Examples describing these phenomena were displayed to students to illustrate what each phenomenon encompasses. The purpose of the exercise was to complement knowledge acquired in lectures by exposing students to real life conditions. They were required to take concepts underlying each phenomenon in abstract terms and turn them into concrete terms through description and interpretation of the situations observed. 
Students were to record and document cultural and behavioural phenomena by photographing selected settings. Two photographs that illustrate each phenomenon were required. A number of rules were established where photographs should be taken for a real life situation to represent indoor or outdoor spontaneous settings. Students write one statement describing the setting in physical, cultural and/or behavioural terms. Simple questions such as: who is doing what, where, how, for how long, and with whom represented the structure of each statement. Assessment criteria were delivered to students; these included how accurately their text and photographs reflect the meaning of the phenomena as discussed in the lectures. How their interpretations show a scholarly understanding of the term, the selection of the setting, and the overall quality of photographs and graphic layout of their submissions were important criteria for evaluating their work and assessing the overall learning outcomes.

An important finding indicates that while all students were able to observe, document, and interpret the information, most of them could not phrase concise statements that describe each setting. However, in a group discussion for debating students work among themselves with the facilitation of the author, they were able to recognize how people behave in a specific environmental situation, their body gestures, degrees of socialization, how they attempt to control their environment, how they shape and transform the physical aspects of the setting to support their activities, enhance their position in space, create views, or block distraction.
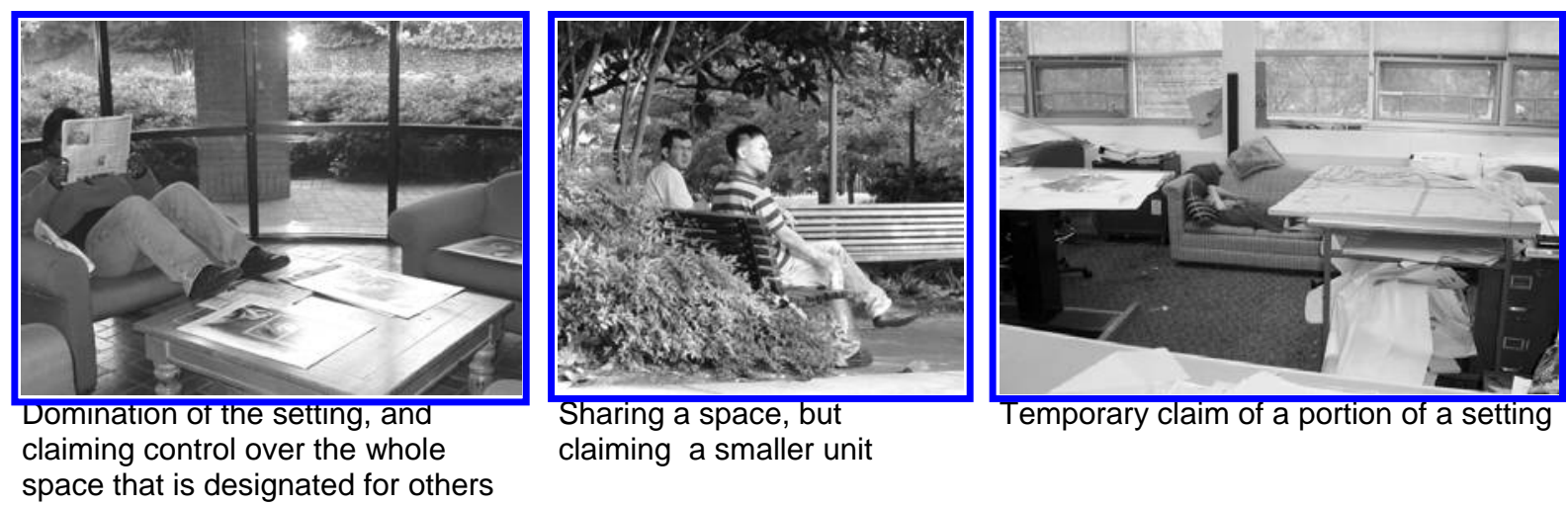

Figure 1: Different environmental settings discussed with students.

\section{Procedural Evaluation and the Multiple Factor Building Appraisal}

To introduce the procedural evaluation mechanism, a survey tool was devised; the purpose of which is to develop students' ability to have control over their learning by establishing links between visual and functional issues of a building or a group of buildings. The exercise is devised to facilitate a deeper understanding of the built environment through self-guided tours. Checklists were provided to offer students a procedure for taking a structured walkthrough and around a building. The evaluation strategy in this context is considered to be impressionistic which increases students' 
awareness by focusing on specific factors (Salama, 1996, 1998; Sanoff, 1991; Shehayeb, 1997).

Students were divided into three groups; each of which conducted a walkthrough exercise utilizing the multiple factor building appraisal tool. Three buildings within KFUPM campus were selected to conduct this exercise; college of environmental design, the central library, and the boys' elementary school located in the campus. A number of key factors were identified and included context, routes, interface, and grouping. Checklists were phrased in the form of questions underlying each factor. The process included the use of notes, sketches, diagrams, and verbal description. Figure 2 illustrates an example sheet used to conduct the procedural evaluation exercise. Questions were designed in a generic manner that reflects the essence of each factor. However, students' attention was drawn to the fact that the list of questions underlying each factor is not exclusive and is introduced to help structure and guide their tours for the purpose of the exercise.

Numerical scores were assigned to the questions to represent the degree of appropriateness underlying each factor using a point scale method. Scores were averaged and an overall score for the building was then computed. Students were required to develop a report that would consider the following:

- Description of the building appraised with the support of photographs and illustrations;

- $\quad$ Appraisal of the building using the checklists with numerical scores assigned for each question;

- $\quad$ Analysis of numerical ratings by computation of an average score for each factor and for the overall score;

- Writing comments or remarks based on their impressions and understanding of the building. 


\section{Factor 3: I NTERFACE}

A building is essentially an enclosure that separates an interior private space from exterior public space. The interface is the crucial meeting place where the inside of the building connects with the outside.

\begin{tabular}{|c|c|c|c|}
\hline & Highly Appropriate & Highly Inappropriate & Score \\
\hline 1. & \multicolumn{2}{|c|}{$\begin{array}{l}\text { How clearly or effectively does the exterior of the building indicate its } \\
\text { interior functions? }\end{array}$} & \\
\hline 2. & \multicolumn{2}{|c|}{$\begin{array}{l}\text { How effectively does the interior of the building connect with the outside } \\
\text { of the building? Are the connections appropriate and functional? }\end{array}$} & -------- \\
\hline 3. & \multicolumn{2}{|c|}{ Are the exits and entrances easily accessible? } & ----- \\
\hline 4. & \multicolumn{2}{|c|}{$\begin{array}{l}\text { Are the various openings related to thoughtful planning of interior? } \\
\text { (Consider entry of light, view, privacy, noise, heat, glare, etc.) }\end{array}$} & ----- \\
\hline 5. & \multicolumn{2}{|c|}{ Are the exit ways appropriate from a safety point of view? } & \\
\hline 6. & \multicolumn{2}{|c|}{$\begin{array}{l}\text { When moving from the exterior of the building to the interior by means } \\
\text { of the main entrance, is the experience pleasant, interesting, or special } \\
\text { in anyway? }\end{array}$} & 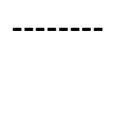 \\
\hline \multirow[t]{2}{*}{7.} & \multicolumn{2}{|c|}{$\begin{array}{l}\text { Has the designer, in your opinion, handled the problem of interface well } \\
\text { in his/her design of this building? }\end{array}$} & ----- \\
\hline & & Average Score $=$ Total $/ 7$ & \\
\hline & $\begin{array}{l}\text { Photographs or other } \\
\text { forms of illustrations that } \\
\text { represent the factor of } \\
\text { "Interface" }\end{array}$ & $\begin{array}{l}\text { A Summary paragraph } \\
\text { should be written describing } \\
\text { how well the design of the } \\
\text { building has addressed the } \\
\text { factor of "Interface" }\end{array}$ & \\
\hline
\end{tabular}

Figure 2: Example sheet utilized to conduct the procedural evaluation exercise

The findings point out that the students were able to make judgements about the built environment and to give reasons for those judgements. However, students' analyses reveal some shortcomings in their abilities to comment, where some of them could not express their concerns verbally and could not write an understandable reporting statement. Also, few students were not able to recognise similarities and differences between the questions. However, they commented that checklists and survey tools for investigating the built environment helped them recognise exactly what to look for 
in the building and to understand relationships between different factors, while comprehending the impact of one factor over others.

\section{Analytical Reflections}

By and large, the results of the two exercises accentuate the value of introducing structured experiential learning tools in lecture courses for assessing buildings or portions of the built environment as an educational medium. Students developed a deeper understanding of the relationship between visual and functional factors and focused on critical issues that go beyond those adopted in traditional teaching practices.

The two widely held conceptions of the built environment; the conceptual/subjective and the physical/objective, are embedded in the exercises. While the first exercise placed emphasis on knowledge acquisition based on students perceptions and interpretations of the actual built environment that are driven by the knowledge delivered in the classroom, the second exercise attempted to develop students understanding of how qualitative aspects of the built environment could be translated into quantifiable measures. However, on the one hand, while the exercises are aimed at introducing structured experiential learning through some form of evaluation research, they do not provide comprehensive panacea to the misconceptions that characterize traditional teaching. On the other hand, the exercises do not address the complexity of the built environment, but they helped students focus on specific aspects of the built environment while bridging the gaps between "what" and "how" types of knowledge.

A large portion of students' education is based on "lessons from the past". Students are typically encouraged to study the existing built environment and attempt to explain it through theories or typologies; always looking at outstanding examples. However, underlying these theories, there are assumptions about the built environment and the people associated with it, and usually these assumptions remain hidden. In this relationship lies the "lesson" to be learnt. Whether people associated with the environment were the actual users of it or were students acting as observers and users, the incorporation of exercises similar to the ones introduced in theory/lecture courses would foster the establishment of links between the existing dynamic environments, the concepts and theories that supposedly explain them, and the resulting learning outcome. Concomitantly, the inherent, subjective, and hard to verify conceptual understanding of the built environment is complemented by the structured, documented interpretation that is performed in a systematic manner. 


\section{Toward a Framework for a Transformative Architectural Pedagogy: The Built Environment as an Open Textbook}

The proposed framework is adapted from the ideas introduced by Necdet Teymur in 1996 in his publication "City as Education". The framework encompasses three domains: major concepts, learning activities, and learning settings. Each domain involves different issues and mechanisms. The first domain includes the concepts of the built environment as an educational object; the study area, the case study, and the educational project; these are outlined below.

\section{The Concept of the Built Environment as an Educational Object}

The built environment is variant, diverse, and complex. Cities, towns, and spaces are major components of this environment, built and lived in, used, designed, planned, analyzed, and represented. They are also experienced, perceived, and studied. They should be re-defined as objects for learning and need to be transformed into scientific objects. In this respect, one should emphasize that in order for an object to be taught and learned, its components should be adapted to specific pedagogic and cognitive orientation that introduces issues about social, and cultural phenomena and their relationship to the built environment.

\section{The Concept of Study Area}

Study area as an educational concept, according to Teymur (1996), can be conceived within two overlapping views. The first view regards it as a legitimate subject for study in the sense that academics always study those parts of the world which they want to understand, change, or contribute to. The second view regards study area as a vehicle, or a medium for achieving specific educational objectives. In both views, evaluation research and experiential learning need to be integral components.

\section{The Concept of Case Study}

This is based on the belief that as a method of qualitative research a case study can accommodate a variety of epistemological orientations and data collection techniques. Thus, the structure and the content of a case study are derived from site surveys, interviews, and true involvement in knowing about successes and failures in existing built environments. Case studies need to address contextual realities within which built environments are created.

\section{The Concept of Educational Project}

The educational project is a key element in resolving paradoxes within the traditional curriculum between academism and professionalism. Rather than attempting to act on the basis of simple simulation of professional practice, educators should make it 
possible to design an educational project in which the primary objective is the development of thinking, learning and enlightenment while developing meaningful design solutions. The introduction of the concept of an educational project would promote both learning together with professionalism. Concomitantly, any educational project would integrate issues about what ought to happen and what is actually happening in the built environment while incorporating theory into real life experiences.

Underlying the preceding concepts the second domain involves three learning mechanisms that can be exemplified by: learning about the built environment, learning from the built environment, and learning to design/plan a workable built environment. Disciplinary concepts include:

- $\quad$ architectural programming and the ability to develop design imperatives and to comprehend constraints;

- $\quad$ post occupancy evaluation and the ability to assess different built environment phenomena and to develop conceptual and systematic understanding of existing buildings; and

- $\quad$ designing where the results of programming and evaluation processes are utilized to conceive solutions for existing or emerging problems.

In these activities, phenomena that exist in a built environment should not be regarded as facts that exist out-there; they should be redefined in order to be studied, researched, and taught.

A number of learning settings and activities are proposed in the third domain to support these activities. Experiential learning would be an integral component of the teaching and learning processes ranging from classrooms to studios to off campus settings. Figure 3 illustrates the proposed framework for a transformative pedagogy in architecture, its underlying concepts, learning mechanisms, activities and the supporting settings. It should be noted that the framework is inclusive where other concepts and learning activities and settings can be introduced based on faculty interests, curriculum structure, resources and desired learning outcomes. 


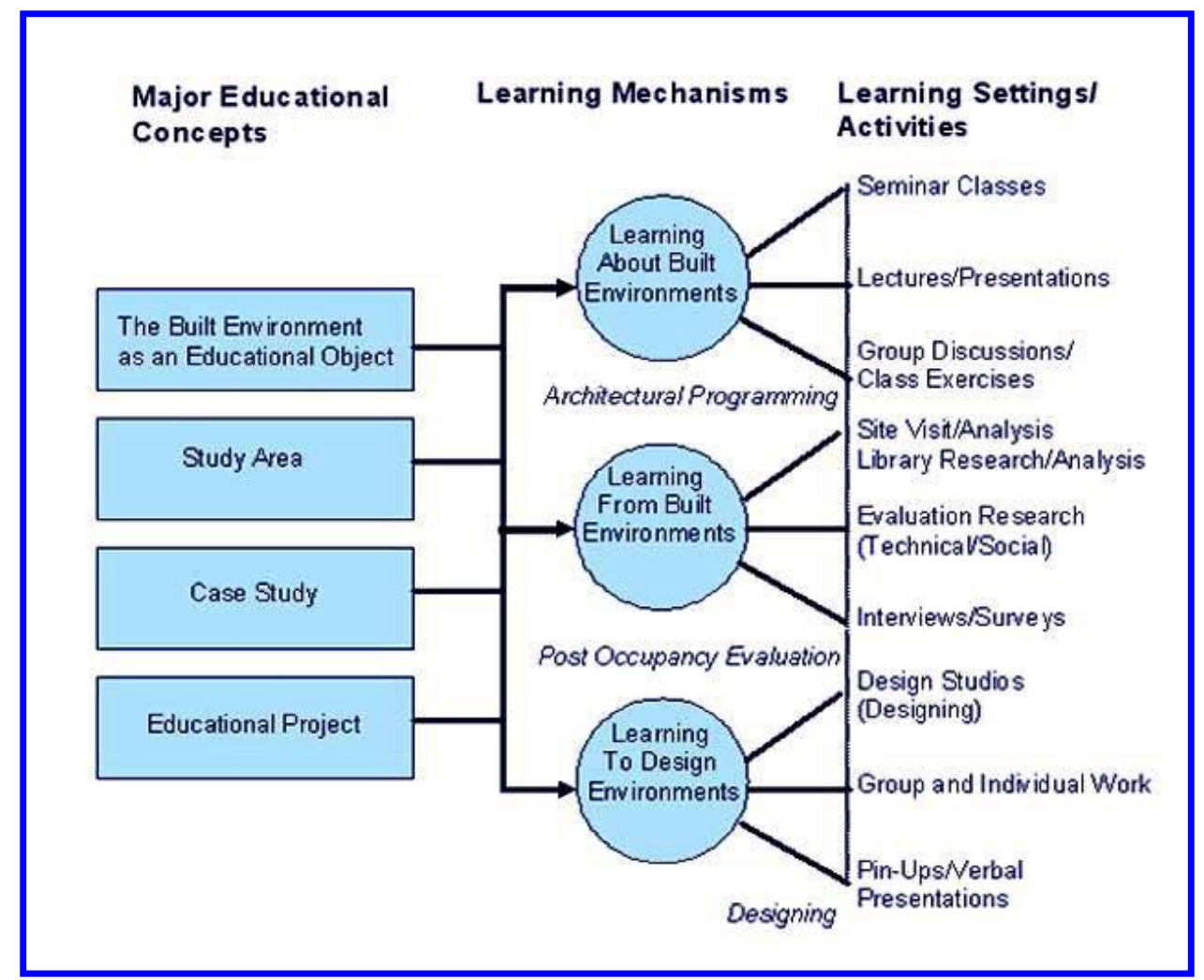

Figure 3 Proposed framework for integrating experiential learning into architectural pedagogy

\section{Conclusion}

The objective of this paper was to suggest ways in which experiential learning can be introduced in architectural pedagogy. Based on the analysis of the literature, five idiosyncrasies and misconceptions in traditional teaching practices were identified. Some tendencies appear to continue to shape traditional pedagogy; these can be exemplified by offering students fragmented knowledge as a product of inquiry - not examining the processes that led up to this product; providing students with ready made interpretations about buildings and built environments as secondary sources of information; the avoidance of dealing with real life conditions, and the missed opportunity of exposing students to structured evaluation research. While these misconceptions vary from one country to another, from one school to another, or even from one academic to another at the same school, the analysis of recent literature corroborates that - in generic terms - they continue to characterize the teaching process of architecture world wide.

The status of research methods courses in fifteen undergraduate architectural programs in eight Middle Eastern countries was examined. The examination reveals a growing awareness of the value of introducing research to undergraduate architecture students. However, it conveys that research has not reached a mature level in several universities within the sample investigated. Therefore, the need for 
introducing research and exposing students to primary sources of information in an active learning process becomes crucial. In response, a case from KFUPM undergraduate program of architecture is developed, analyzed, and presented in a manner that illustrates forms of desired integration of experiential learning and evaluation research. A more comprehensive framework is conceptualized to complement traditional teaching practices. It encompasses a number of educational concepts and the supporting learning mechanisms, activities and settings. It is the perception and position of this author that the incorporation of research into undergraduate architectural education represents a true frontier. Concomitantly, it is believed that implementing this framework would foster the capabilities of future architects to be critical thinkers while introducing any change in the environment.

\section{Acknowledgment}

The author expresses his thanks to King Fahd University of Petroleum and Minerals KFUPM and to the students of ARC 482 elective - 2004.

\section{References}

Anthony, Kathryn (1991) Design Juries on Trial: The Renaissance of the Studio. New York: Van Nostrand Reinhold.

BCEURU. Boyer Commission on Educating Undergraduates in the Research University. (1998) Reinventing Undergraduate Education: A blueprint for America's Research Universities.

http://notes.cc.sunysb.edu/Pres/boyer.nsf/webform/images/\$File/boyer.txt

Boyer, Ernest \& Mitgang, Lee (1996) Building Community- A New Future for Architectural Education and Practice. New Jersey: Carnegie Foundation for the Advancement of Teaching.

Cuff, Dana (1991) Architecture: The Story of Practice. Cambridge, Mass: MIT Press.

Fisher, Thomas (2004) Architects Behaving Badly: Ignoring Environmental Behavior Research. Harvard Design Magazine. 21, http://www.gsd.harvard.edu/research/publications/hdm/current/21 fisher.html

- Gerlenter, Mark (1988) Reconciling Lectures and Studios. Journal of Architectural Education. Vol. 41 (2), 46-52.

Groat, Linda (2000) The Architect as Artist or Scientist? A modest proposal for the Architect-as-Cultivator. In K. D. Moore (ed) Culture-Meaning-Architecture: Critical Reflections on the work of Amos Rapoport. pp 127-150. London, UK: Ashgate. 
A.M. Salama: Learning from the Environment: Evaluation Research and Experience Based Architectural Pedagogy

Habraken, John (2003) Questions that will not Go Away: Some Remarks on Long Term Trends in Architecture and their Impact on Architectural Education. Keynote Speech: Proceedings of the Annual Conference of the European Association of Architectural Education-EAAE. Hania. Crete, Greece. pp 31-42.

http://www.openhouse-int.com/competi/JOHN\%20HABRAKEN\%20PAPER.pdf

Juhasz, Joseph (1981) The Place of Social Sciences in Architectural Education. Journal of Architectural Education, Vol. 33 (3), 2-8.

Keeton, Morris and Tate, Pamela (eds) (1978) Learning by Experience. San Francisco, CA: Jossey Bass Publishers.

Koch, Aaron, Schwennsen, Katherine, Dutton, Thomas \& Smith, Deanna (2002) The Redesign of Studio Culture, Studio Culture Task Force, Washington, DC: The American Institute of Architecture Students-AIAS.

- Mazumdar, Sanjoy (1993) Cultural Values in Architectural Education. Journal of Architectural Education. Vol. 46 (4), 230-237.

Morrow, Ruth (2000) Architectural Assumptions and Environmental Discrimination: The Case for More Inclusive Design in Schools of Architecture. In D. Nicol and S. Pilling (eds) Changing Architectural Education: Towards a New Professionalism. London, UK: Spon Press. pp 43-48.

Morrow, Ruth, Parnell, Rosie \& Torrington, Judy (2004) Reality versus Creativity. CEBE-Transactions: Journal of the Centre for Education in the Built Environment. Vol. 1 (2), 91-99.

Nicol, David and Pilling, Simon (eds) (2000) Changing Architectural Education: Towards a New Professionalism. London, UK: Spon Press.

O'Reilly, William (ed) (1999) Architectural Knowledge and Cultural Diversity. Lausanne, Switzerland: Comportments.

Rapoport, Amos (1994) The Need for What Knowledge. Plenary Speech: Proceedings of the $25^{\text {th }}$ Annual International Conference of the Environmental Design Research Association-EDRA, St. Antonio, TX. pp 35-39.

Romice, Ombretta \& Uzzell, David (2005) Community Design Studio: a Collaboration of Architects and Psychologists. CEBE-Transactions: Journal of the Centre for Education in the Built Environment. Vol. 2 (2), 73-88.

Salama, Ashraf (1995) New Trends in Architectural Education: Designing the Design Studio. Raleigh, NC: Tailored Text and Unlimited Potential Publishing. 
A.M. Salama: Learning from the Environment: Evaluation Research and Experience Based Architectural Pedagogy

Salama, Ashraf (1996) Environmental Evaluation: A New Voice for Integrating Research into Architectural Pedagogy. Journal of Architectural Research. Cairo: Al Azhar University. November. pp 7-23.

Salama, Ashraf (1998) A New Paradigm in Architectural Pedagogy. In J. Teklenburg et al. (eds) Shifting Balances: Changing Roles in Policy, Research, and Design. Eindhoven, Netherlands: EIRSS Publishers. pp 128-139.

Salama, Ashraf (1999) Incorporating Knowledge about Cultural Diversity into Architectural Pedagogy. In W. O'Reilly (ed) Architectural Knowledge and Cultural Diversity. Lausanne, Switzerland: Comportments. pp 135-144.

Salama, Ashraf, O'Reilly, William, \& Noschis, Kaj (eds.) (2002) Architectural Education Today: Cross Cultural Perspectives. Lausanne, Switzerland:

Comportments.

Salama, Ashraf (2002) Environmental Knowledge and Paradigm Shifts: Sustainability and Architectural Pedagogy in Africa and the Middle East. In A. Salama, W. O'Reilly \& K. Noschis I. (eds) Architectural Education Today: Cross Cultural Perspectives. Lausanne, Switzerland: Comportments. pp 51-63.

Salama, Ashraf (2005) Skill-Based/Knowledge-Based Architectural Pedagogies: Toward an Alternative for Creating Humane Environments. Keynote Speech: Proceedings of the $7^{\text {th }}$ International Conference of the International Association for Humane Habitat-IAHH, Mumbai, India.

Sanoff, Henry (1991) Visual Research Methods in Design. New York, NY: Van Nostrand Reinhold.

Sanoff, Henry (1992) Integrating Programming, Evaluation, and Participation in Design. England: Avebury.

Sanoff, Henry (2003) Three Decades of Design and Community. Raleigh, NC: College of Design, North Carolina State University.

Sara, Rachel (2000) Introducing Clients and Users to the Studio Project: A Case Study of a Live Project. In D. Nicol \& S. Pilling (eds) Changing Architectural Education: Towards a New Professionalism. London, UK: Spon Press. pp 77-83.

Schaffner, Ann, Stebbins Leslie \& Wayman, Sally (1999) Quality Undergraduate Education in a Research University: The Role of Information Literacy. Proceedings of the $9^{\text {th }}$ National Conference of the Association of College and Research LibrariesACRL: Racing Toward Tomorrow. Detroit, Michigan. pp 1-5.

Schon, Donald, A. (1981) Learning a Language, Learning to Design. Architectural Education Study. Cambridge, MA: Consortium of East Coast Schools of Architecture. 
A.M. Salama: Learning from the Environment: Evaluation Research and Experience Based Architectural Pedagogy

Schon, Donald, A. (1983) The Reflective Practitioner: How Professionals Think in Action. New York, NY: Basic Books.

Schon, Donald, A. (1985) The Design Studio: An Exploration of Its Tradition and Potentials. London, England: RIBA Publications.

- Schon, Donald, A. (1988) Toward a Marriage of Artistry and Applied Science in the Architectural Design Studio. Journal of Architectural Education. Vol. 41 (4), 16-24.

Seidel, Andrew. (1994) Knowledge Needs the Request of Architects. In Seidel, A. Banking on Design: Proceedings of the $25^{\text {th }}$ Annual International Conference of the Environmental Design Research Association-EDRA, St. Antonio, TX. pp 18-24.

Shehayeb, Dina, K. (1997) Understanding the Built Environment: Qualitative Research Methods for Designers. Proceedings of the Sixth Conference-Al Azhar Engineering International Conference. Cairo, Egypt: Department of Architecture, Al Azhar University. Digital Proceedings.

- Stamp, Arthur, E. (1994) Jungian Epistemological Balance: A Framework for Conceptualizing Architectural Education. Journal of Architectural Education. Vol. 48 (2), 105-112.

Sutton, Sharon (1984) Should Behavioral Studies Be Integrated Into the Design Studio. Architectural Record. July. pp 43-48.

Teymur, Necdet (1996) City as Education: Habitat II Edition. London, England: Question Press.

UIA - UNESCO Charter for Architectural Education (1996) Revised Version - 2004 http://www.mimarlarodasi.org.tr/UIKDocs\%5Ccharterforarchitecturaleducation.pdf

Zube, Ervin (1981) Environmental Evaluation: Perception and Public Policy. Belmont, CA: Wadsworth Inc. 
This article has been cited by:

1. Rowan Watson. 2014. Learning from the Environment and Making: Using Analysis and the Senses. Journal for Education in the Built Environment 9:1, 69-88. [Abstract] [Full-text] [PDF] [PDF Plus] 